\title{
An Effective Method for the Monitoring of Stag Beetle (Lucanus cervus (Linnaeus, 1758) (Coleoptera: Lucanidae)) larvae
}

\author{
Zafer AYAZ1 \\ Derya ÇiFTÇi² \\ ${ }^{1}$ Gazi University, Information Technology Department, Ankara, TURKEY \\ ${ }^{2}$ Veysel Karani Mahallesi, Siirt Üniversitesi Kezer Lojmanları 3E Blok No:8, SiliRT, TURKEY \\ e-mails: 'zafer@gazi.edu.tr, ${ }^{2}$ dcanpolat@gmail.com \\ ORCID IDs: ${ }^{10000-0001-7667-7921 ~ 20000-0002-7670-4392 ~}$
}

\begin{abstract}
Lucanus cervus (Linnaeus, 1758) is involved in the Near Threatened (NT) danger category in the IUCN Red List. It plays an important role in the ecosystem, nutrient cycling, and the decomposition process of wood. Its larvae live under or in damp and decaying trees. We designed an equipment to ensure the detection and the long-term monitoring of Lucanus cervus and many other insect larvae that complete their larval stages in a wood tissue without destroying their habitats. The equipment developed is an audio listening device that amplifies the larval sounds. This device was designed as a 4-stage structure with a sensor stage, low and high pass filter stage, voltage gain sound amplifier stage, and output stage. This device was used for the first time in the larvae's natural environment. With this new equipment, listening was performed on decaying trunks in the Amanos Mountains, which are included in the spreading area of Lucanus cervus akbesianus Planet, 1896, located within the borders of Hatay province in June-July 2017. The presence of the larvae of Lucanus cervus akbesianus was detected in oak tree trunks, and sound recording was performed. Accordingly, the larvae made approximately 5 clicks in a series and left a 7-8 second gap between two series. It is considered that the audio listening device developed in this study is an effective method for the detection of other saproxylic beetles larvae in decaying wood.
\end{abstract}

Key words: Coleoptera, Stag Beetle Larva, Audio listening device, Piezo Sensor

Ayaz, Z., Çiftçi, D., (2021). An effective method for the monitoring of stag beetle (Lucanus cervus (Linnaeus, 1758) (Coleoptera: Lucanidae)) larvae, Journal of the Entomological Research Society, 23(1), 69-81. 
Ayaz, Z., Çiftçi, D.

\section{INTRODUCTION}

Lucanus cervus (Linnaeus, 1758) known as stag beetle, is one of the species of the largest known terrestrial insects in Turkey. The adults are 25-89 mm long, including mandible length (approximately 25-49 mm for females, approximately $30-89 \mathrm{~mm}$ for males) (Bardiani, Chiari, Maurizi, Tini, Toni, Zauli, Campanaro, Carpaneto \& Audisio, 2017).

The stag beetle is an obligate saprophytic species. Its larvae are present at, under, or inside the section of the damp and decaying wood close to the soil surface, and usually in light soils. The adults feed on fruit and tree sap. They usually fly in the evening. While the larvae generally develop in the oak in Ukraine, they are present on large trunks of deciduous trees such as chestnut, oak, willow, ash, poplar, and linden on the European side of Turkey (IUCN, 2020).

The females lay their large eggs, which are $3 \mathrm{~mm}$ in length, one by one. However, they lay approximately 20 of them in dead bark cracks (Huerta \& Rodriguez, 1988; Baraud, 1993).The eggs hatch within two to four weeks, and the larvae come out. The larval stage, which lasts for five or six years, passes by feeding in these tree trunks. This slow development is due to both the low nutrient quality (low nitrogen content) of decayed trees and the large size that needs to be achieved at maturity. After the last larval stage, during which it may exceed $10 \mathrm{~cm}$ in length, it enters the pupae in the tree or soil, near the log (Sánchez, 1983).

While the larval stages of Lucanus cervus do not differ significantly in shape, there is a significant increase in their size. Typical lucanid larvae are white-looking or creamy, soft, oligopod, and roughly "C-shaped" on the side view, and have transverse folds in their abdominal segments and a longitudinal anal cleft. The head capsule is reddish-brown to orange in color and more hardened compared to its body. There are no ocelli and ommatidium, the antennas are elongated, and pubescence developed only on the front part of the body (Bardiani et al, 2017). The larvae have a typical sound-producing apparatus formed by two sclerosing (hardened tissue) organs on the second and third pairs of legs, respectively. A pair of soft, convex, and translucent oval bumps are formed above the abdomen on the dorso-posterior side, and these structures are large and close to each other in the inner parts. Very dense, strong, and numerous short brownish setae are present on the ventral surface of the distal abdominal segment of the larvae. The mandible of Lucanus larvae is large and overly curved (Bardiani et al, 2017).

Larval stridulation is approximately continuous and may serve to inform adults about the location of young individuals (Ratcliffe, 1991).

Typical predators of stag beetles are bird species such as woodpecker, magpie, crow, kestrel, and owl. Wild pigs and badgers also prey on pupae on the ground. They may also fall prey to species such as hedgehogs, foxes, shrews, and mole (Reißmann, 2020).

Lucanus cervus is included in the Near Threatened (NT) danger category in the IUCN Red List (IUCN, 2020) and the NT danger category in the European Red List of 
An effective method for the monitoring of stag beetle

Saproxylic Beetles (Cálix, Alexander, Nieto, Dodelin, Soldati, Telnov, Vazquez-Albalate, Aleksandrowicz, Audisio, Istrate, Jansson, Legakis, Liberto, Makris, Merkl, Mugerwa Pettersson, Schlaghamersky, Bologna, Brustel, Buse, Novák \& Purchart, 2018). Although the species is commonly found in Europe, a significant decline is observed in the north and central parts of the distribution area. It is assumed that future trends of European forests will pose serious threats to this species. Thus, the species will soon be qualified in the Vulnerable (VU) category (IUCN, 2020). Furthermore, the species is included in Appendix III (Protected Fauna Species) according to the BERN Convention on the Conservation of European Wildlife and Natural Habitats.

Stag beetle has national conservation status in England (Hylyman, 1992), and the species is also in large protected areas in Romania and Ukraine. In Spain, they are protected as species of 'special concern' (Verdú \& Galante, 2004). The species is listed as Endangered in the British Red Data Book, Endangered in Germany and Sweden, Vulnerable in Denmark, and Critically Endangered in the Czech Republic (Nieto \& Alexander, 2010).

Many action plans regarding the conservation of the Lucanus cervus were implemented in many countries in Europe (London Wildlife Trust, 2020a, 2020b; Hertfordshire Environmental Forum, 2020; Joint Nature Conservation Committee-JNCC, 2020; REF Impact Case Studies, 2020), and long-term monitoring studies were carried out as a result of these action plans (Harvey, Hawes, Gange, Finch, Chesmore \& Farr, 2011; Čížek, 2006; Campanaro, Hardersen, Toni \& Grasso, 2010).

In Turkey, an action plan study was carried out for the Akbez stag beetle (Lucanus cervus akbesianus Planet, 1896) in Hatay province by the Ministry of Forestry and Water Affairs, VII Regional Directorate, Hatay Department (Akman, Biler, Hasbenli, Demirel, Çiftçi, Çiftçi, Can \& Muratlı, 2017).

Acoustic devices provide the non-destructive, remote, and automatic detection and monitoring of hidden insect infestations for the pest manager, regulators, and researchers. The effectiveness of acoustic devices in detecting cryptic insects, predicting population density and in distribution maps depends on many factors such as sensor type and frequency range, the substrate structure, interface between the sensor and substrate, the distance between insect and the sensors, and evaluation time, size and behavior of insect (Mankin, Hagstrum, Smith, Roda \& Kairo, 2017).

Ultrasonic sensors are particularly effective for detecting wood-boring insects at their best because background noise is negligible at frequencies of $>20 \mathrm{kHz}$ and ultrasonic signals are attenuated in wood much less than air. The problems in distinguishing sounds produced by target species from other sounds have prevented the use of acoustic devices. However, new devices and signal processing methods have significantly increased detection reliability. New methods take into account the spectral and temporal pattern features that are prominently visible in insect sounds but invisible in the background noise and vice versa. As reliability and ease of use increase and costs decrease, acoustic devices will take a significant place as cryptic insect detection and monitoring tools in the future (Mankin et al, 2017). 
Since biting and trembling patterns of Lucanus cervus larvae can be detected in tree trunks, acoustic listening technique can be used to detect without destroying the habitat. Research planning, with acoustic listening and recording methods, can have a great potential use in habitat research aimed at providing information about rare species (Harvey et al, 2011). Monitoring of the improved acoustic series of Lucanus cervus larvae has been proposed, but field tests have not been conducted yet (Harvey et al, 2011).

This study aims to introduce detecting larvae using acoustics devices that will not damage the larval habitats and that will be effective in reducing the research workload for the detection and monitoring of Lucanus cervus and other saproxylic beetles.

\section{MATERIALS AND METHODS}

The field studies were carried out in the parts within the borders of Hatay province of the Amanos Mountains, which are included in the distribution area of Lucanus cervus akbesianus Planet, 1896 (Fig. 1), in June-July 2017. The black pine (Pinus nigra) forests mixed with deciduous trees are present in the study area. Also, The kermes oak (Q. coccifera), hairy oak (Q. cerris), taurus fir (Abies cilicia spp. cilicica), cedar (Cedrus libani) and red pine (Pinus brutia) forests grow in the Amanos Mountains (Lise, 2006).

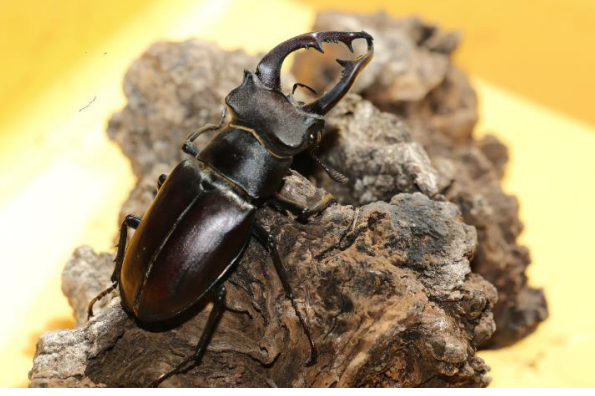

Fig. 1. Akbez Stag Beetle (Lucanus cervus akbesianus Planet, 1896) male.

The field studies were by conducted two researchers and the larval sounds were searched in many rotting tree trunks (about 110 trees, especially oak trees), using the new audio electronic equipment. The technical specifications of the new audio electronic equipment are presented below (Fig. 2). Recordings were made for a period of three minutes for each tree. The biting sounds of larvae were recorded from 17 decaying trees. Only one of the decayed trees that was subjected to sound recording was was cut into pieces and the larvae were removed to verify whether it was a Lucanus cervus larvae. The detected sounds were recorded by a mobile phone. The recording was then copied onto a PC, studied, and edited with Adobe audition audio editing programme.

In the equipment developed, which is shown in Fig. 2, the part number (1) is the sensor, the part number (2) is the connection to the recorder, the part number (3) is 
An effective method for the monitoring of stag beetle

the earphone output, the part number (4) is the input signal adjustable potentiometer between the audio amplifier stage and output stage, and the part number (5) is the power button of the circuit. When the circuit is operated, the sounds can be recorded with the recording equipment connected to the output from the part number (2) while larval sounds are listened from the part number (3).

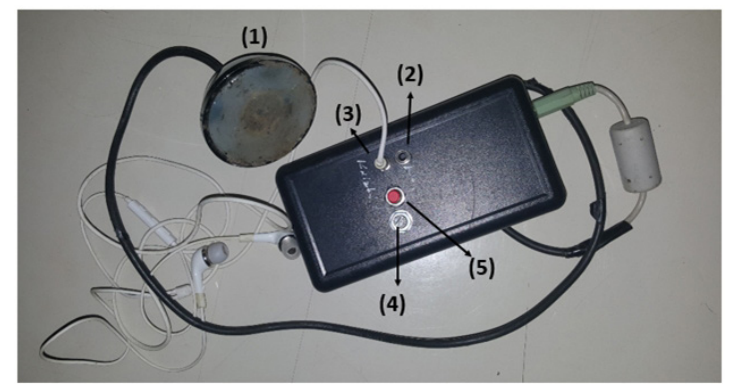

Fig. 2. Listening device that increases larval stridulation.

The electronic equipment developed in the study was designed as a 4-stage structure with a sensor stage ( $1^{\text {st }}$ stage), low and high pass filter stage $\left(2^{\text {nd }}\right.$ stage), voltage gain sound amplifier stage ( $3^{\text {rd }}$ stage), and output stage $\left(4^{\text {th }}\right.$ stage). The schematic representation of this 4 -stage structure is presented in Fig. 3.

In the equipment designed, initially, the Piezo Sensor signal source was used as the receiving element. Then, the amplitude of the audio signal passing through the low pass and high pass passive filter stage was increased with a high gain signal amplifier. Along with the final amplification for the output stage, it was directly connected to an earphone or a computer or another similar device that can perform sound analysis.
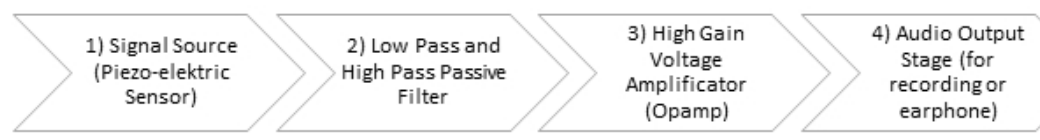

Fig. 3. Schematic diagram of the electronic equipment designed.

\section{Components of the listening device}

\section{Sensor stage (Piezo crystal)}

Although the Piezo Sensor, also known as piezoelectric or piezo crystal elements, was discovered by Pierre Curie in 1880, the industrial use of this electronic element began after the 1950s. Piezoelectric sensors can convert mechanical stress into an electrical charge. The ability of a piezoelectric material to convert mechanical stress into an electrical charge is called the Piezoelectric Effect. The word piezoelectric was derived from the Greek word 'piezein' and means pushing, pressing, and squeezing. The piezoelectric effect is a reversible effect, which means that we get some electrical charge at the output when we apply mechanical stress to the piezoelectric material. When we provide an electrical charge to the sensor, the element is stressed or compressed. The working principle of the crystal is presented in Fig. 4 (Components 101, 2020). 


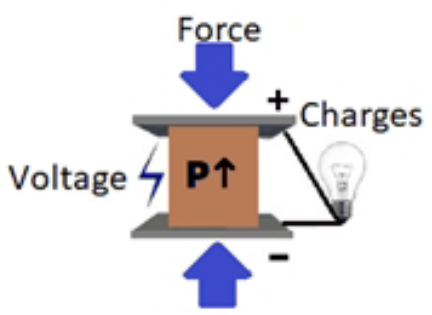

Fig. 4. Working principle of the piezoelectric material (Components 101, 2020).

Due to this feature of the piezoelectric effect, it is used for stress detection or stress generation. When the element is disengaged, they generate electrical signals starting from low levels due to environmental vibration or surface pressure (Murata Manufacturing Company Limited, 2020).

Piezoelectric sensors are used in many areas such as electrical power generation, contact microphone, ultrasonic receiver or transmitter, ultrasonic cleaner, instrument microphone, and water leak and flow detectors. Recently, they have also started to be used as bio-acoustic sensors. Through the contact of the piezoelectric sensors with the human body, biological data such as blood flow condition and heartbeat can be detected and processed electronically (Bhalla, Moharana, Talakokula \& Kaur, 2017).

A standard 35-mm-diameter Piezoelectric sensor, which is very easily available in the electronics market and has a resonance sensitivity of $2-40 \mathrm{Khz}$, was preferred for the vibration sensor equipment. A sample piezoelectric crystal is presented in Fig. 5.

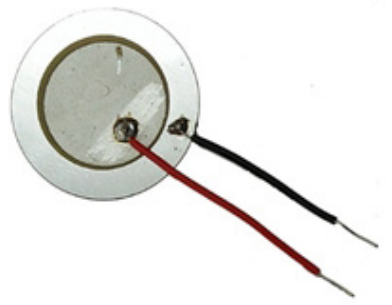

Fig. 5. Sample of 35-mm Piezo Crystal sensor (Components 101, 2020).

To prevent the Piezoelectric sensor, which is a sound receiving element, from being affected by environmental distortions, it was directly connected to the filter stage of our electronic circuit with a shielded $50-\mathrm{cm}$ cable connected to the chassis ground and a 3.5-mm jack. The Piezo crystal was fixed with hot silicone sealant in a housing to increase the direct contact surface on log structures. Thus, it was aimed to have maximum contact on the log by obtaining a curved and softer surface compared to the crystal in the front part. The view of the piezo crystal in its housing is presented in Fig. 6.

\section{Low and high pass filter}

Since the sounds received through the circuit are subject to distortion by other sound-producing sources, quality sound reception is affected if this filter stage is not used. Therefore, audio signals were planned to transmit audio frequencies in the target 
An effective method for the monitoring of stag beetle

range before being subjected to amplification. Resistor-Condenser or Resistor-Coil pairs can be used for this process. We preferred to use the Resistor-Condenser pair $(R C)$ in the filters for the equipment developed. The RC Low Pass Filter is a simple filter circuit that passes a low frequency band consisting of a resistor and condenser. The gain is constant between $0 \mathrm{~Hz}$ and the cutoff frequency (fc). At the cutoff frequency, the low frequency gain decreases by $3 \mathrm{~dB}$. The frequencies between $0 \mathrm{~Hz}$ and the cutoff frequency (fc) are band-pass frequency, and the frequencies higher than fc are band-quenching frequency. The gain in band-quenching frequency is very low. The frequency range can be calculated using the formula of $\mathrm{fc}=1 /(2$. $\pi$.R.C) (Aspen Core Network, 2020a). Considering the sound range of stag beetles, in the calculation made to pass frequencies between $0-12 \mathrm{Khz}$ without loss, the frequency cutoff value of $11483 \mathrm{~Hz}$ is achieved with a 220-ohm resistor and 63-nf condenser. The structure of low and high pass filters is presented in Fig. 7, and the operating performance chart of the low pass filter is presented in Fig. 8.

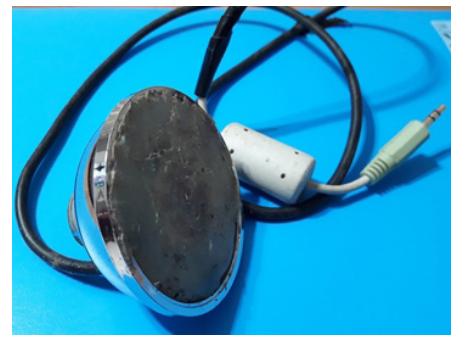

Fig. 6. View of the piezo crystal in its housing.

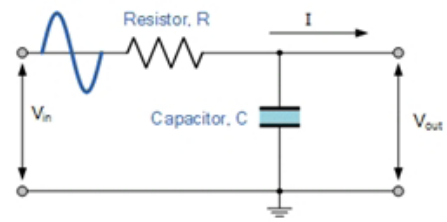

Fig. 7. Electronic schematic representation of the Low Pass Filter (Aspen Core Network, 2020a).

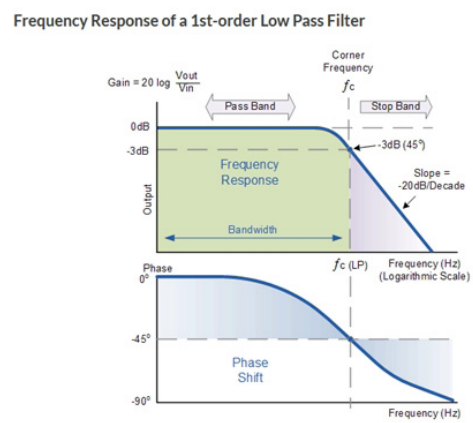

Fig. 8. Operating performance of the low pass filter (Aspen Core Network, 2020a). 


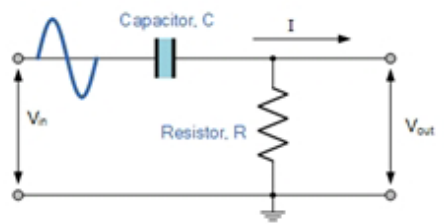

Fig. 9. Electronic scheme of the High Pass Filter (Aspen Core Network, 2020b).

\section{High pass filter}

With the high pass filter, which is the second filter stage, audio signals at a certain frequency are allowed to pass (Aspen Core Network, 2020a). The high pass filter structure is presented in Fig. 9 and the operating performance chart of the high pass filter is presented in Fig. 10.

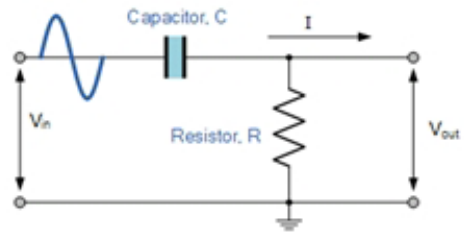

Fig.10. Operating performance of the high pass filter (Aspen Core Network, 2020b).

In the calculation made with the formula of $\mathrm{fc}=1 /(2$. $\pi$.R.C) at this stage, it was calculated that the frequencies above $9645 \mathrm{~Hz}$ could pass with a 330-ohm resistor and a 50 -nf condenser.

With the sequential use of low and high pass filters, a filter stage that allows the passage of the frequency band between 9645 and $11483 \mathrm{~Hz}$ by attenuating and suppressing the signals that are not in this frequency range was obtained. Due to this feature, it was possible to obtain maximum clean sound in the range of sound emitted by Stag beetle larvae.

\section{Signal Amplifier}

An amplifier stage was needed for the signal that was filtered at the desired bandwidth but still very weak to reach an audible and analytical level. Standard uses of opamp amplifiers are presented in Fig. 11 (Starecki \& Wieczorek, 2017).
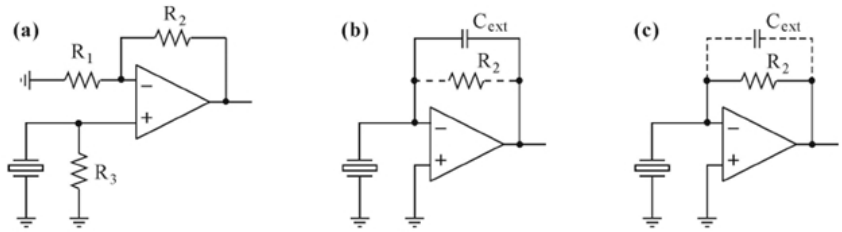

Fig. 11. Basic configurations of preamplifiers dedicated for use with piezoelectric sensors: (a) voltage amplifier, (b) charge amplifier, (c) transimpedance amplifier (taken from Starecki \& Wieczorek, 2017). 
An effective method for the monitoring of stag beetle

The logic of the voltage booster circuit presented in Fig. 11a was used in our equipment. The gain on this amplifier is calculated with the formula gain $=1+(R 2 /$ $\mathrm{R} 1)$. R1 resistor and R2 resistor were made variable by using a fixed value resistor and a multi-turn trimpot resistor, respectively, so that the gain settings of the circuit would be flexible.

In our study, the Opamp integrated amplifier circuit, which was used as an amplifier in the voltage gain mode, was selected due to the following features:

Since the device is portable, it should be able to draw low voltage and little current.

The gain rate should be adjustable.

The ratio of harmonic distortion should be very low.

The input level should have a low and wide impedance ratio.

The opamp series amplifier integrations with all these features together were examined, and it was found that NE5532 op-amp integrations, which are generally preferred in guitar microphone sound amplifier circuits, were suitable for this use.

The part of the sound amplifier stage made as a circuit is presented in Part 1 in Fig. 12. The sound amplifier stage was assembled in accordance with the standard amplifier circuit published by the NE5532 integrated manufacturers. One of the gain resistors was provided by using a multi-turn trimpot resistor so that the gain setting would be optimum. Part 2 on the audio listening circuit is the second amplifier stage, which was considered as the Output Stage (Fig. 12). These stage features are discussed in detail in the Output Stage section.

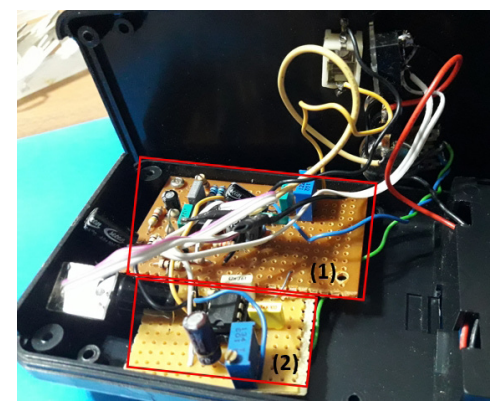

Fig. 12. Interior view of the Audio Listening Device.

\section{Output stage}

The part of the audio listening device assembled as the Output Stage is presented in Part 2 in Fig. 12. A second amplifier stage was used to bring the sounds directly to an audible level at the output stage. Thus, sounds can be heard with headphones or an external speaker. An interconnection was established before the output stage to allow the use of a computer or similar device for sound analysis.

At first, the electronic card NE5532 Op-amp integrator was assembled as a card in a way to be raised $100 x$ as in the datasheet documents given by the manufacturer. The 
output point of the circuit was connected to the recording equipment output connection and output stage input. LM386 integrator, one of the standard opamp integrators, was used as the output stage integration. The output stage audio output level was taken under control with the $10 \mathrm{Kohm}$ adjustable potentiometer used in the input of the output stage. Since opamp was used in the circuit, the gain setting was adjusted to the optimum value using a multi-turn trimpot resistor in one of the gain resistors.

\section{CONCLUSION AND DISCUSSION}

In the present study conducted with equipment designed to ensure the detection and long-term monitoring of many insect larvae that complete their larval stages in a wood tissue without destroying their habitats, listening was performed on decaying trunks of such different trees as oak, Taurus fir, cedar and red pine. To detect the vibration and biting sounds produced on tree trunks by the larvae of Akbez Stag Beetle (Lucanus cervus akbesianus), listening was performed at the ground level and 0.5 $\mathrm{m}$ and $1 \mathrm{~m}$ above the ground level in order to measure the sensitivity of the device, and no significant decrease was observed in sound gain.

Akbez Stag Beetle larvae were detected on the trunks of decaying old oak trees. The detected sounds were recorded by a mobile phone and analyzed with Adobe audition audio editing programme. Consequently, the larvae made approximately 5 clicks in a series and left a 7-8 second gap between two series (Figs. 13-14).

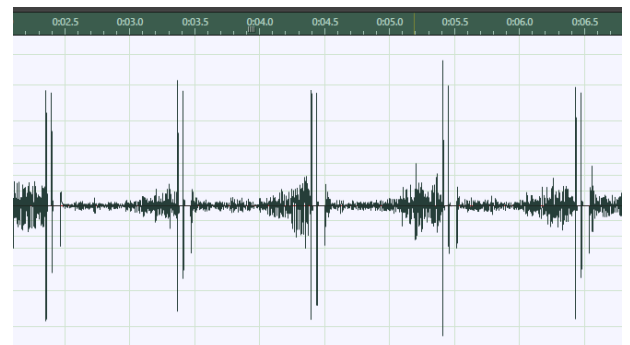

Fig. 13. Stridulation spectrum of Akbez Stag beetle larvae (for 5 clicks).

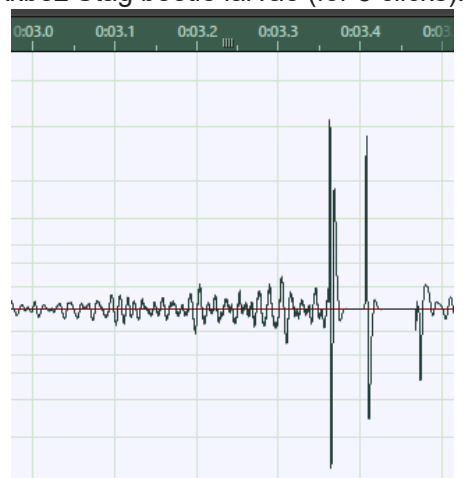

Fig. 14. Stridulation spectrum of Akbez Stag beetle larvae (for 1 click). 
An effective method for the monitoring of stag beetle

For the determination of the presence of $L$. cervus larvae in decaying wood, Harvey et al. (2011) used terrarium set up in the laboratory to record the biting sound of the larvae. Their purpose was to detect the larvae in the wood without disturbing the larval habitat. For this purpose, a simple piezoelectric transducer and microphone were placed closed to the wood inside the terrarium and connected to an amplifier unit. They determined that the biting sound of $L$. cervus and other saproxylic species (D. parallelipipedus) could be determined and each species has a different and characteristic sound pattern. In our study, a sound listening device with piezoelectric sensors with sound amplifier was used. Thus, sound recording was made by amplifying the very low sounds in the decaying wood. Another difference from the other study is that the device trials were made in the natural environment of the larvae. Audio analysis of biting the wood sound of $L$. cervus akbesiana larvae recorded in natural environment is similar to the audio analysis of Harvey et al (2011) in situ. The data we have obtained as a result of the study show that the device is suitable and sufficient for use in the field. It is thought that this device can be used not only for the larvae of Lucanus species, but also for the detection of other saproxylic beetles larvae without destroying their habitats.

During in the field studies, precision and caution should be exercised when using Piezoelectric sensors. Piezoelectric sensors are an electronic circuit element that converts mechanical stress into electrical energy, and conversely, generates mechanical stress when there is electrical input. Therefore, the resulting signal amplitude increases in parallel with the stress rate applied to the sensor. The input sensitivity should be low, and the gain should be high for the sound amplifier circuit to have a very sensitive input. The signal to be generated by the piezoelectric sensor when it is contacted with the trunk with a hard impact while the circuit is working during the trunk observation is at a high level and damages the integration at the sound amplifier stage. To avoid this problem, observation should be made by energizing the listening circuit after the sensor is contacted with the log to be monitored before the circuit is energized.

\section{ACKNOWLEDGMENT}

We would like to thank the Hatay Department of the Nature Conservation and National Parks VII Regional Directorate of the Ministry of Forestry and Water Affairs, the Republic of Turkey, and Ekoplan Engineering Consultancy Inc. for carrying out the project of "Species Action Plan for the Conservation of the Populations of Akbez Stag Beetle (Lucanus cervus akbesianus) Species Living Within the Borders of Hatay Province and Their Habitats". Furthermore, we would like to express our gratitude to Prof. Dr. Abdullah HASBENLi (Ankara, Turkey), who was the coordinator of this project, and other colleagues working on the project. 
Ayaz, Z., Çiftçi, D.

\section{REFERENCES}

Akman, B., Biler, L., Hasbenli, A., Demirel, E., Çiftçi, M.C., Çiftçi, D., Can, Ş.B. \& Muratı, S. (2017). Akbez Geyik Böceği (Lucanus cervus akbesianus) Türünün Hatay Ili Sınırlarında Yaşayan Popülasyonlarının ve Yaşam Alanlarının Korunmasına Yönelik Tür Eylem Planı. T.C. Ormanve Su İşleri Bakanlığı, Doğa Koruma ve Milli Parklar Genel Müdürlüğü, VII. Bölge Müdürlüğü, Hatay Şube Müdürlüğü, Hatay, 50 pp.

Aspen Core Network (2020a, July 14). Electronic Tutorials, Low Pass Filter, Cambridge, USA. Retrieved from https://www.electronics-tutorials.ws/filter/filter_2.html.

Aspen Core Network (2020b, July 14).Electronic Tutorials, High Pass Filter, Cambridge, USA. Retrieved from https://www.electronics-tutorials.ws/filter/filter_3.html.

Baraud, J. (1993). Les coléoptères Lucanoidea de l'Europe et du Nord de l'Afrique. Bulletin mensuel de la Société Linnéenne de Lyon, 62(2), 42-64.

Bardiani, M., Chiari, S., Maurizi, E., Tini, M., Toni, I., Zauli, A., Campanaro, A., Carpaneto, G. M. \& Audisio P. (2017). Guidelines for the monitoring of Lucanus cervus. Nature Conservation, 20, 37-78.

Bhalla, S., Moharana, S., Talakokula, V. \& Kaur, N. (2017). Piezoelectric Materials: Applications in SHM, Energy Harvesting and Biomechanics. Retrieved from http://ebookcentral.proquest.com/lib/ gazi-ebooks/detail.action?doclD=4756882.

Cálix, M., Alexander, K.N.A., Nieto, A., Dodelin, B., Soldati, F., Telnov, D., Vazquez-Albalate, X., Aleksandrowicz, O., Audisio, P., Istrate, P., Jansson, N., Legakis, A., Liberto, A., Makris, C., Merkl, O., Mugerwa Pettersson, R., Schlaghamersky, J., Bologna, M.A., Brustel, H., Buse, J., Novák, V. \& Purchart, L. (2018) (2020, July 1). European Red List of Saproxylic Beetles. Brussels, Belgium IUCN. Retrieved from http://www.iucnredlist.org/initiatives/europe/publications.

Campanaro A., Hardersen S., Toni I. \& Grasso D.A. (2010). Monitoring of Lucanus cervus by means of remains of predation (Coleoptera: Lucanidae). Entomologia Generalis, 33:79-89.

Čížek, L. (2006). Metodika monitoringu evropsky významného druhu roháč obecný (Lucanus cervus). AOPK ČR, II.F.9, 1-5.

Components 101 (2020, July 15). Piezoelectric sensors. Retrieved from https://components101.com/ sensors/piezoelectric-sensor.

Harvey, D.J., Hawes, C.J., Gange, A.C., Finch, P., Chesmore, D. \& Farr, I. (2011). Development of non-invasive monitoring methods for larvae and adults of the stag beetle, Lucanus cervus. Insect Conservation and Diversity, 4, 4-14.

Hertfordshire Environmental Forum (2020, July 4). A Biodiversity Action Plan for Hertfordshire. Retrieved from http://hertssustainability.org.uk/policies/4589511176.

Huerta, A. \& Rodríguez, J.L. (1988). SOS Por la FaunaEspañola, 100 Especies en Peligrode Extincion. EdicionesFondo Natural, Madrid, $223 \mathrm{pp}$.

Hyman, P.S. (revised Parsons, M.S.). 1992. A review of the scarce and threatened Coleoptera of Great Britain. Part 1. UK Nature Conservation: 3. Joint Nature Conservation Committee, Peterborough, 484 pp.

IUCN (2020, July 9). The IUCN Red List of Threatened Species, Version 2020-2. Retrieved from https:// www.iucnredlist.org.

Joint Nature Conservation Committee-JNCC (2020, July 8). UK priority species pages-Version 2, Lucanus cervus (Linnaeus, 1758) Stag Beetle. Retrieved from http://jncc.defra.gov.uk/_speciespages/425.pdf.

Lise, Y. (2006). Amanos Dağları AKD063. In G. Eken, M. Bozdoğan, S. İsfendiyaroğlu, D.T. Kılıç, Y. Lise (Eds). Türkiye'nin Önemli Doğa Alanları Cilt 2 (pp. 434-443). Doğa Derneği, Ankara.

London Wildlife Trust (2020a, July 5). Stag Beetle an Advice Note for its Conservation in London. Retrieved from http://downloads.gigl.org.uk/website/stag_advice.pdf.

London Wildlife Trust (2020b, July 5). Stag Beetle How to Help its Conservation in London. Retrieved from https://www.wildlondon.org.uk/sites/default/files/2019-06/stag-beetle-london-wildlife-trust-advicenote-2016.pdf. 
An effective method for the monitoring of stag beetle

Mankin, R.W., Hagstrum, D.W., Smith, M.T., Roda, A.L. \& Kairo, M.T. (2017). Perspective and Promise: A Century of Insect Acoustic Detection and Monitoring. American Entomologist, 57(1), 30-44.

Murata Manufacturing Company Limited (2020, July 14). Piezoelectric Ceramics Sensors (Piezotite), Catalogue Number P19E-7. Retrieved from http://www.farnell.com/datasheets/43406.pdf.

Nieto, A. \& Alexander, K.N.A. (2010). European Red List of Saproxylic Beetles. Luxembourg: Publications Office of the European Union, $45 \mathrm{pp}$.

Ratcliffe, B.C. (1991). The Lucanidae and Passalidae (Insecta: Coleoptera) of Nebraska. Great Plains Research: A Journal of Natural and Social Sciences, 1(2), 249-282.

REF Impact Case Studies (2020, July 5). Royal Holloway University of London, Conservation of the stag beetle, Lucanus cervus. Retrieved from https://impact.ref.ac.uk/casestudies/CaseStudy. aspx?Id=30239.

Reißmann, K. (2020, July 5). Der Hirschkäfer (Lucanus cervus Linnaeus, 1758). Retrieved fromhttp:// www.kerbtier.de/Pages/Themenseiten/deHirschkaefer.html

Sánchez, J. (1983). El coleccionismo de insectosestáprovocando la regresiónde algunasespecies. Quercus, 11, 28.

Starecki, T. \& Wieczorek, P.Z. (2017). A High Sensitivity Preamplifier for Quartz Tuning Forks in QEPAS (Quartz Enhanced Photo Acoustic Spectroscopy) Applications. Sensors, 17(11), 2528.

Verdú, J.R. \& Galante, E. (2004). Behavioural and morphological adaptations for a low-quality resource in semi-arid environments: dung beetles (Coleoptera, Scarabaeoidea) associated with the European rabbit (Oryctolagus cuniculus L.). Journal of Natural History, 38, 705-715. 